\title{
An Investigation of Efficacy and Hope as Predictors of Academic Motivation
}

\author{
Hira Arooj* \\ Tanvin Ijaz
}

\begin{abstract}
The present study aimed at exploring the predictors of academic motivation of adolescents by analyzing the academic efficacy and academic hope. The sample was consisted of 1581 students from nine towns of Lahore. Sampling was done through area probability sampling strategy. The data was collected by using translated and adapted Academic Efficacy Scale (Arooj \& Ijaz, 2017), Academic Hope Scale (Arooj \& Ijaz, 2017), and Academic Motivation Scale (Arooj \& Ijaz, 2017). Pearson Product Moment Correlation analysis showed the existence of positive relationship between academic efficacy, academic hope and intrinsic and extrinsic academic motivation. Stepwise Regression Analysis displayed two models. In these models, academic efficacy and academic hope predicted intrinsic academic motivation and contributed variance of $24 \%$ and $13 \%$, respectively. Furthermore, the Stepwise Regression Analysis for extrinsic academic motivation showed two models in which academic efficacy and academic hope contributed variance of $22 \%$ and $12 \%$ respectively.
\end{abstract}

Keywords: School students, academic motivation, academic efficacy, academic hope, regression, relationship

\footnotetext{
* Founder \& Counseling Psychologist, Child Guidance Center, Lahore, Email: hiraarooj@hotmail.com

** Associate Professor, Government College University, Lahore, Email: tazvinijaz@gcu.edu.pk
} 


\section{Introduction}

Academic motivation, a domain specific motivation, is a significant predictor of achievement in schools (Durik, Lovejoy, \& Johnson, 2009). Motivation is a complex psychological phenomenon and has been already studied widely in the field of education (Zimmerman, 2008). It has many outreaching factors that influence its level in students (Rowell \& Hong, 2013) however; more focus is needed on the cognitive aspects.

Individuals who usually look similar perform differently in academics because they think and feel in various ways about themselves. Hence, they select varied ways of actions depending upon their perceptions about themselves (Turgut, 2013) and their inner characteristics (Komarraju, Karau \& Schmeck, 2009). Children with different self-beliefs and traits demonstrate miscellaneous levels of cognitive and socio-emotional engagement in schools. Therefore, school related experiences are important as they shape and regulate their motivational level for better performances in academics (Linnenbrink \& Pintrich, 2002).

Recently, the theory of Self Determination conceptualized three kinds of motivational constructs; the first one is autonomous motivation that refers to the engagement of students in the academic activities with a sense of volition. This not only includes intrinsic motivation but also the well internalized extrinsic motivation. The second kind of motivational construct is the controlled motivation. It refers to the external regulation of incentives, rewards and punishment along with the introjected regulation (a partial internalization) of the desire for the self approval, self-esteem and the regulation of avoidance of shame. Third construct is named as a-motivation. It is the absence of motivation and intention to work (Deci \& Ryan, 2010). Vallerand et al. in 1992 designed a scale to measure the tenets of self-determination theory.

Motivation is divided into two main types known as intrinsic and extrinsic motivation. The intrinsic motivation has been studied by the researchers since the early 1970 s. It is also driven by the self-interests and enjoyment in the task and these enjoyments and interests exist within the individual rather than the external pressures (Ryan \& Deci, 2000). This kind of motivation is present in the form of a natural motivational tendency in an organism and is a critical element in cognitive, physical and social development. Students who are motivated intrinsically usually take part in academic tasks enthusiastically to improve their proficiency and for enhancing their abilities. This motivation also appears with the 
efficacious belief of students about their skills that in turn smoothes their path to be an efficient agent while reaching the targeted goals. These students are interested in mastering the study topics not just scoring good grades (Wigfield, Guthrie, Tonks, \& Perencevich, 2004).

Moreover, Ryan and Deci (2000) also explained in their research that extrinsic motivation is the opposite of intrinsic motivation. It comes from the influences of surroundings i.e. outside of the individual. In this type of motivation, it is difficult to explain as from where do people get the motivated, then act under its influence and continue to push themselves with persistence. Researchers described common extrinsic motivators as rewards and rein forcers and sometimes threat of punishment for showing the desired behavior and refraining from the misbehaviors. Competition is an extrinsic motivator in the school environment as it promotes good performance, and urges to win over other students. It does not encourage the learner to simply enjoy the intrinsic rewards of the activity. More examples of extrinsic incentives include the desire to win a trophy and a cheering crowd (Benabou \& Tirole, 2003).

In 1995, Fortier, Vallerand and Guay proposed a motivational model of school performance by considering cognitive evaluation theory and self determination theory. This model has proposed two basic views. First one is that autonomous academic motivation is influenced positively through the combination of perceived academic selfdetermination and competence. Secondly, the autonomous academic motivation affects the school performance of a student directly (Fortier, Vallerand, \& Guay, 1995).

When a student would feel himself incompetent and believes that he can't do well in academics then his autonomous academic motivation would be low, affecting their school performance badly. And if they would feel self determined (capacity of choosing the right among several courses of actions) in the educational environment and also experience higher level of academic competence (sense of being effective in academics) then their autonomous academic motivation will raise automatically improving the school performance (Fortier et al., 1995). Hence, it is evident from this model that the person's feelings and believes about his self plays an important role in enhancing his motivation levels.

Self-efficacy is the self-believe and confidence of a person in his abilities to accomplish a specific task at a designated level by organizing and regulating his performance in a certain order (Artino, 2012). It is concerned with the evaluation of specific tasks (Linnenbrink \& Pintrich, 2002). It is also domain specific i.e. people evaluate themselves by 
focusing on special functioning domains (Bandura, 2006). Academic self-efficacy particularly focuses on the self-belief of students regarding their educational activities. It deals with the confidence of people about their productive performance and achievement at designated levels in particular academic area (Artino, 2012).

Self-efficacy has four core features which are identified by Bandura (2005). These features greatly contribute to the keep the human motivation level intact. Intentionality is the first feature- individuals motivate themselves by focusing on the challenges and signifying performance standards to master negative discrepancies. Further, he explained the phenomenon of forethought by mentioning that people use their personal resources by evaluating their abilities and the performance standards. Self-reactiveness is the adjustment of efforts made in order to achieve the desired goals. After attaining the goals people have pursued they reflect on their abilities, perceive their efficacy and set higher standards for themselves. This process is termed as self-reflectiveness (Bandura, 2001). These core features form a cycle of adjustments that people usually make as they learn and develop with time, and achieve or adjust their personal goals (Bandura, 2005).

Extensive research has been done till now to find the factors that inhibits or promotes academic motivation. Many constructs have been introduced by the researchers and among those constructs hope is the important cognitive factor (Snyder, Rand, \& Sigmon, 2002). Hope is the cognitive process in which a person thinks about his goals and moves towards those goals and finds ways to achieve those goals with motivation. Snyder et. al., (2002) defined academic hope in the same way as hope by focusing on the particular area of education. It is the thinking process which involves motivation to move toward particular academic goal by working upon the strategies to achieve those goals.

Hope is like a problem-solving fuel which helps the individuals along with their teachers and parents to understand how to work with them and help them in developing their own strengths. Hope is the ability of an individual to articulate their goals consistently and clearly (goals thinking), then develop stepping plans for achieving those goals (pathways thinking), and lastly, persevere in case of obstacles (agency thinking) (Snyder et. al., 2000).

Students experiencing little hope in life have elevated level of anxiety, especially in test-taking situations. The underlying reason of that anxiety is related to the student's inability of using productive feedbacks in an adaptive and constructive manner from their poor experiences for improving their future performances in academics (Onwuegbuzie \& 
Snyder, 2000). Such students are prone to unconstructive ponderings and self-doubt. This then hinder with their potential of attending the cues for better performance i.e. studying and test-taking respectively (Lopez, Rose, Robinson, Marques, \& Pais-Ribeiro, 2009).

On the other hand the students with high hope do not derogate their capabilities when they fail, and also they do not let the failures in their life to affect their self-worth. Hence, the high-hope students show more adaptive thoughts on the failure feedback (Onwuegbuzie \& Snyder, 2000).

Hopeful beliefs allow students to make strong commitments, set their goals, and to work effectively for attaining the desired goals. When students lack hope their academic expectations lower automatically and hence their academic performances suffer. Individuals with high hope usually experience less anxiety competitive and test-taking situations (Snyder, Shorey, \& Rand, 2008). They also obtain higher grades throughout their elementary, junior and high-school as compared to lowhope students. Higher hopes predict higher grades and lower drop-out rates in academic life. It also predicts higher graduation rates (Snyder et. al., 2002).

Hope flows from one person to another person's life influencing each other for pursuing goals. Effects of hope in students can be increased by eliminating various barriers in educational community. A student who can identify the obstructions hindering his performance and growth can easily generate various pathways for circumventing such hindrances. These barriers include schedule problems, lack of resources, stressful societal events, problems stemming from the available physical facilities, parental disinterest, and health-related epidemics. An individual who is good in handling the hindrances and moves persistently towards his goal is the one who achieves in school settings (Snyder et. al., 2002).

\section{Literature Review}

As discussed above motivation plays a significant role in the learning environment. The child who seems academically motivated feels himself more involved in the learning-related activities, and considers school important. Martin \& Greenwood(1995) explained the reasons of poor academic motivation of students in relation to their pessimistic beliefs about their ability for academic attainment. These pessimistic believes come in existence due to chronic life stress, learning disabilities, developmental delay, difficult temperament, and depression making it 
harder for an individual to perform better in schools by lowering their motivational level. Students who failed in school, stop trying to learn as they develop the belief that they can't do better. The attitude of adults also sometimes lowers the academic motivation by influencing efficacious believes and hope.

According to the recently documented researches the link between the self-efficacious believes and the intrinsic motivation is positive and meaningful. The results also indicate that self-efficacy negatively correlates with the a-motivation and it is not related to a measure of extrinsic motivation(Walker, Greene and Mansell in 2006; Ferla, Valcke, \& Cai, 2009).

Helmer and Grolnick (2016) found in their research that people high in self-efficacy are more likely to see a challenge. This either makes them to be able to cope resiliently or vice versa in difficult times. Also, researchers found academic self-efficacy as a better predictor of success because students with high self-efficacy can recognize the academic challenges in a better way (Zajacova, Lynch, \& Espenshade, 2005). Hence, such students can cope in the disappointing academic situation (Helmer \& Grolnick, 2016) and can attain success through preservation of intrinsic and extrinsic motivation (Wood, Hilton, \& Hicks, 2014).

Academic self-efficacy plays important role in motivating the self and enhancing the learning process (Sarkoc \& Oksuz, 2017) and hope is essential in maintain the self esteem of the person. It has a considerable positive association with the self-worth (Foote, Piazza, Holcombe, Paul, \& Daffin, 1990) signifying the existence of efficacious believes and motivation about the betterment in life. This significant relationship was also investigated by Marques, Lopez, \& Pais-Ribeiro (2011) in their experimental study for the intervention of hope in school children to observe better motivation and academic achievement. Results suggested that the hope intervention can increase psychological strengths of student. Furthermore, academic efficacy and academic hope, the cognitive competencies, predict each other and have path towards academic specific variables. They also help in the better academic attainment (Feldman \& Kubota, 2015).

The researches documented in Pakistan report the relationship between academic motivation, efficacy and hope. However, the literature is limited. Therefore, this study attempts to fill the gap in literature. The 
purpose of this research is to find the relationship of the academic motivation with academic efficacy and academic hope along with the model that predicts academic motivation more significantly. Moreover, the academic motivation will be studied as two separate constructs; the intrinsic academic motivation and extrinsic academic motivation. In the view of above literature, it was hypothesized that:

1. There would be a significant relationship among the academic efficacy, academic hope and academic motivation.

2. Academic efficacy and academic hope would significantly predict the intrinsic academic motivation of students.

3. Academic efficacy and academic hope would significantly predict the extrinsic academic motivation of students.

4. There would be a significant gender difference in the academic motivation of school students.

\section{Method}

\section{Sample}

Sample of individuals used for this research comprised of 1581 students from the government schools of Lahore. Students from the mainstream population were selected in the sample with the age ranging from 11-15 years $(M=13.37, S D=1.07)$. The data was collected from 18 schools of the Lahore present in all nine towns. 90 students were selected from each school from three clusters of $7^{\text {th }}, 8^{\text {th }}$ and $9^{\text {th }}$ grade $(30$ students from each grade). Moreover, gender was divided into two groups; male students $(n=768)$ and female students $(n=813)$. There were more female participants specifying the gender imbalance in the study. Area probability sampling was used for recruiting the participants in the present study. It is a multistage sampling in which geographic areas are selected with known probability.

\section{Inclusion criteria}

Participants between the 11-15 years were selected for the data collection. All participants were from $7^{\text {th }}, 8^{\text {th }}$ and $9^{\text {th }}$ grade. Students from the $10^{\text {th }}$ grade were excluded because of their unavailability. Students 
from the private schools were also excluded because of the 2-3 different private school systems in Lahore.

\section{Measures}

Academic Efficacy Scale (Midgley et al.; 2000). This scale is originally developed in the University of Michigan in 2000 by Midgley et al. It focuses on the belief of the students that how successfully they can achieve the academic goals at a designated level. The instrument consists of 5 items and it is measured on a 5-point Likert scale (1-5 indicating strongly disagree to strongly agree). It is valid for the students of middle school and its reliability $(\alpha)$ is 0.78 . Urdu translation of the scale was used for reader feasibility (Arooj \& Ijaz, 2017). The reliability coefficient of the scale in current study is 0.72 .

Academic Hope Scale (AHS; Sympson, 1999). This scale is originally developed by Dr. Sympson in 1999. The scale includes 9 items rated on a 5-point likert scale from 1: strongly disagree to 5: strongly agree. The Academic Hope Scale consisted of two factors: Agency and Pathways. It is valid for the age range of 13-17 years and its reliability is 0.88 . Urdu translation of the scale was used for reader feasibility (Arooj $\&$ Ijaz, 2017) which is valid for the age ranging from 11-17 years. The reliability coefficient of the scale in current study is .78.

Academic Motivation Scale (AMS; Vellarand, et al., 1992). This scale analyzes motivation of students from the high school and contains seven subscales. These subscales assess the intrinsic motivation towards knowledge, accomplishments and stimulation, as well as external, introjected and identified regulation, and a-motivation. It is developed by Dr. Vellarand et al in 1992. It contains 28 items assessed on a 5-point scale. Its reliability is $0.88(\alpha=0.88)$. Urdu translation of the scale was used for reader feasibility (Arooj \& Ijaz, 2017) with an internal consistency of .84 .

\section{Procedure}

Data was collected from different Government Schools of Lahore after the approval of Research Board of GC University and the respective schools using the abovementioned scales. The targeted population was 
approached during school hours. Before collecting the data, their consent was taken and necessary instructions were delivered to them about how to fill the questionnaires by the researcher. Moreover, their confidentiality was assured. Self-report questionnaires along the demographic sheet were given to the participants individually. Urdu version of the questionnaires was provided for reader feasibility. Afterwards the data was entered in SPSS for descriptive and inferential analysis. Almost 35 forms were discarded because of the fake information by the participants. Thus, the analysis was done on the 1581 number of participants. It took almost one and a half month in data collection and three months in data entry. Data entry was further checked by selecting every $25^{\text {th }}$ entry. The research was completed in almost one year.

\section{Results}

Pearson Product Moment Correlation and Multiple Stepwise Regression were run on the data using SPSS 21.0 to obtain the results.

Table 1

Mean, Standard Deviation and Cronbach's Alpha of Measuring Instruments $(N=1581)$

\begin{tabular}{lcccc}
\hline Instruments & Mean & $\begin{array}{c}\text { Standard } \\
\text { Deviation }\end{array}$ & No. of Items & $\begin{array}{c}\text { Cronbach's } \\
\text { Alpha }\end{array}$ \\
\hline AES & 21.54 & 2.81 & 5 & .72 \\
AHS & 33.84 & 4.54 & 8 & .78 \\
AMS & 109.80 & 9.45 & 28 & .84 \\
\hline
\end{tabular}

Note. AES $=$ Academic Efficacy Scale, AHS= Academic Hope Scale, $\mathrm{GS}=$ Grit Scale, $\mathrm{AMS}=$ Academic Motivation Scale

Table 1 shows internal consistency (cronach alpha) of the instruments. The results show high internal consistency of academic motivation scales $(\alpha=0.84)$. The internal consistency of academic efficacy $(\alpha=0.72)$ and academic hope $(\alpha=0.78)$ are moderate. 
Table 2

Mean, Standard Deviation and Correlations of Academic Efficacy, Academic Hope and Academic Motivation ( $N=1581)$

\begin{tabular}{lcccccc}
\hline & \multicolumn{5}{c}{$r$} & \\
Variables & $A E$ & $A H$ & $I M$ & $E M$ & $M$ & $S D$ \\
AE & - & $.68^{* *}$ & $.49^{* *}$ & $.47^{* *}$ & 21.54 & 2.82 \\
$\mathrm{AH}$ & & - & $.61^{* *}$ & $.58^{* *}$ & 33.83 & 4.54 \\
$\mathrm{IM}$ & & & - & $.75^{* *}$ & 53.22 & 6.37 \\
$\mathrm{EM}$ & & & & - & 55.70 & 4.87 \\
\hline
\end{tabular}

${ }^{* *} p<.01$. Note. $\mathrm{AE}=$ Academic Efficacy, $\mathrm{AH}=$ Academic Hope, $\mathrm{IM}=$ Intrinsic Motivation, $\mathrm{EM}=$ Extrinsic Motivation, $\mathrm{PW}=$ Pathway, $\mathrm{AG}=$ Agency, $\mathrm{M}=$ Mean, $\mathrm{SD}=$ Standard Deviation

Table 2 shows the correlation matrix between the variables; academic efficacy, academic hope and intrinsic and extrinsic academic motivation. It shows significant positive moderate correlation among all variables. However, the relationship between intrinsic and extrinsic academic motivation is strong.

Table 3

Multiple Stepwise Regression Analysis for Intrinsic Academic Motivation

\begin{tabular}{|c|c|c|c|c|}
\hline \multicolumn{5}{|c|}{ Intrinsic Academic Motivation } \\
\hline \multirow[b]{2}{*}{ Variable } & \multirow[b]{2}{*}{ Model 1} & \multirow[b]{2}{*}{ Model 2} & \multicolumn{2}{|c|}{ Coefficients } \\
\hline & & & $\beta$ & $95 \% \mathrm{CI}$ \\
\hline Constant & 29.35 & 22.10 & & \\
\hline Efficacy & $1.11 * * *$ & $.32 * * *$ & .49 & {$[1.01,1.21]$} \\
\hline Hope & & $.71 * * *$ & .51 & {$[.64, .79]$} \\
\hline$R^{2}$ & .24 & .37 & & \\
\hline$F$ & $497.79 * * *$ & $480.79 * * *$ & & \\
\hline$\Delta R^{2}$ & .24 & .14 & & \\
\hline$\Delta F$ & 497.79 & 352.54 & & \\
\hline
\end{tabular}

Stepwise regression analysis was used to test the predictors of intrinsic academic motivation. The analysis has showed two models. In 
the first model academic efficacy predicts academic motivation and contributes $24 \%$ of variance in it which means that the change of one unit in academic efficacy causes the variance of 24 units in intrinsic academic motivation $\left(R^{2}=.24, F(1,1579)=497.79, p<.001\right)$. The model $2,37 \%$ of variance in academic motivation is caused by both academic efficacy and academic in which hope contributes an additional $14 \%$ variance in intrinsic academic motivation $\left(R^{2}=.37, F(2,1578)=\right.$ $480.79, p<.001)$.

Table 4

Multiple Stepwise Regression Analysis for Extrinsic Academic Motivation

\begin{tabular}{lcccc}
\hline & \multicolumn{3}{c}{ Extrinsic Academic Motivation } \\
\hline & & \multicolumn{3}{c}{ Coefficients } \\
\cline { 3 - 5 } Variable & Model 1 & Model 2 & Beta & $95 \% \mathrm{CI}$ \\
\hline Constant & 38.12 & 32.97 & .47 & {$[1.01,1.21]$} \\
Efficacy & $.82^{* *}$ & $.28^{* *}$ & .47 & {$[.64, .79]$} \\
Hope & & $.51^{* *}$ & & \\
$R^{2}$ & .22 & .34 & & \\
$F$ & $451.69^{* *}$ & $411.73^{* *}$ & & \\
$\Delta R^{2}$ & .22 & .12 & \\
$\Delta F$ & 451.69 & 289.29 & \\
\hline \multicolumn{5}{c}{ Note. $\mathrm{N}=1581 . \mathrm{CI}=$ Confidence Interval. ${ }^{* * *} p<.001$}
\end{tabular}

Stepwise regression analysis was used to test the predictors of extrinsic academic motivation. The analysis has showed three models. In the first model academic efficacy predicts academic motivation by $22 \%$ which means that the change of one unit in academic efficacy contributes the variance of 22 units in extrinsic academic motivation $\left(R^{2}=.22, F(1\right.$, $1579)=451.69, p<.001)$. The model 2 suggests that $34 \%$ of variance is caused in extrinsic academic motivation by both academic efficacy and academic hope in which academic hope contributes an additional variance of $12 \%$ in extrinsic academic motivation $\left(R^{2}=.34, F(2,1578)=\right.$ 451.73, $p<.001)$. 
Table 5

Mean, Standard Deviation and t-Value of Intrinsic and Extrinsic Academic Motivation in Male and Female Students $(N=1581)$

\begin{tabular}{lcccccccc}
\hline & \multicolumn{3}{c}{ Males } & \multicolumn{3}{c}{ Females } & \multicolumn{4}{c}{$95 \%$ CI } \\
\cline { 2 - 9 } Variables & $M$ & $S D$ & $M$ & $S D$ & $t$ & $p$ & $L L$ & $U L$ \\
\hline Intrinsic & 52.47 & 6.72 & 53.92 & 5.94 & - & .00 & - & -.92 \\
Motivation & & & & & 4.54 & & 2.07 & \\
Extrinsic & 55.23 & 5.05 & 56.14 & 4.65 & - & .00 & - & -.42 \\
Motivation & & & & & 3.69 & & 1.38 & \\
\hline
\end{tabular}

Note: $\mathrm{M}=$ Mean, $\mathrm{SD}=$ Standard Deviation, $\mathrm{CI}=$ Confidence Interval, $\mathrm{LL}=$ Lower Limit, $\mathrm{UL}=$ Upper Limit, $\mathrm{t}=\mathrm{t}$-value, $\mathrm{p}=$ significance level $<.01$

Table 5 of independent sample t-test suggests a statistically significant gender difference among school children in terms of their intrinsic and extrinsic academic motivation. The results show that females $(M=53.92, S D=5.92)$ have high intrinsic academic motivation than males $(M=52.47, S D=6.72)$. This difference was found to be statistically significant at $t(1581)=-4.54, p<.01$. Also, the females $(M=$ $56.14, S D=4.65)$ have significantly high extrinsic academic motivation than males $(M=55.23, S D=5.05)$. This difference was found to be statistically significant at $t(1581)=-3.69$.

\section{Discussion}

Academic motivation is a complex psychological phenomenon (Zimmerman, 2008) which has many outreaching factors influencing its level in students (Lowell \& Hong, 2013). The main purpose of this research was to analyze the cognitive predictors along with the predictors from the intrapersonal competencies of the individual to outreach the academic motivation and to explore its level in students. Inferential statistics were used on the variables; academic efficacy, academic hope, grit and academic motivation to carry out results.

The analysis has showed that the academic efficacy, academic hope share positive and strong relationship with each other and moderate relationship with intrinsic and extrinsic academic motivation. This is supported by the previous research in 2014 by Husain who found a relationship between self-efficacy and academic motivation in participants from business school. Ersanli (2015) stated that motivation has external and internal factors contributing in the stimulation of desire to accomplish the goals. Both factors motivate people to follow and 
achieve their goals and also motivate them to overcome obstructions in their path. It happens because people with higher efficacious beliefs do not give up when confronted with difficulties (Zimmerman, Bandura, \& Pons, 1992). Moreover, hope intervene the level of motivation (Marques, Lopez, \& Ribeiro, 2011).

Moreover, the analysis has also showed that academic efficacy and academic hope predicts intrinsic and extrinsic academic motivation and contributes variance in them at a certain level. Academic efficacy predicted intrinsic and extrinsic motivation in a finest way among all other variables and this is supported by Burgler and his co-worker in their research in 2015. They found that self-efficacy predicts variance in intrinsic and extrinsic motivation and it predicts more variance in intrinsic than extrinsic motivation. The current study also found that academic efficacy contributes more variance in intrinsic than extrinsic academic motivation.

Academic hope is also found to be the predictors of academic motivation. This founding is supported by the previous researches by PinaWatson, López, Ojeda, and Rodriguez (2014) and Rojas (2015). PinaWatson, López, Ojeda, and Rodriguez indicated that hope predicts academic motivation in adolescents.

\section{Conclusion}

It is concluded in the current research that there exists a relationship among academic efficacy, academic hope and intrinsic and extrinsic academic motivation. It is also analyzed that the beliefs about academic tasks are the best predictors that help in raising the motivation level of students in schools. Also, academic efficacy shares a strong relationship with academic hope and together they both raise the intrinsic and extrinsic motivation. Moreover, it is also found in the current study that cognitive process of students cause variation in their intrinsic academic motivation more than the extrinsic academic motivation.

\section{Implications}

The current study will provide literature for the researchers and experimenters on the relationship of efficacy, hope and motivation in academic context. It is a general conception in schools to provide a competitive environment for better motivational results and performances. We know from the previous study (Benabou \& Tirole, 
2003) that a competitive environment lowers the long term interest in learning along with the intrinsic motivation (Amabile, DeJong, \& Lepper, 1976). So, the school practitioners need to devise interventions for better learning rather than better grades. Hence, this study will help Pakistani school administrations to devise the curriculum with new perspective, taking cognitive process (efficacious believes and hope) of students in consideration. This study will also help in understanding the specific ratio of predictors causing variations in intrinsic and extrinsic academic motivation. It will also help the future researchers to devise the intervention plan that will help to work on specific targeted points for rising academic motivation of students for better academic performance. Furthermore, as this research is specifically focusing on the positive psychology of school students that's why the intervention plans will be of minimal risk. 
An Investigation of Efficacy and Hope as Predictors of Academic Motivation 95

\section{References}

Arooj, H. \& Ijaz,T. (2017). Academic efficacy, academic hope and grit as predictors of academic on motivation in adolescents. Government College University, Lahore.

Artino, A. R. (2012). Academic self-efficacy: From educational theory to instructional practice. perspectives on medical education, 1(2), 7685.

Bandura, A. (2001). Social Cognitive Theory: An Agentic Perspective. Annual Review of Psychology, 52(1), 1-26.

Bandura, A. (2005). The Evolution of Social Cognitive Theory. In K. G. Smith \& M. A. Hitt (Eds.), Great Minds in Management. UK: Oxford University Press.

Bandura, A. (2006). Guide for constructing self-efficacy scales. SelfEfficacy Beliefs of Adolescents, 5, 307-337.

Benabou, R., \& Tirole, J. (2003). Intrinsic and extrinsic motivation. The Review of Economic Studies, 70(3), 489-520.

Bugler, M., McGeown, S. P., \& St Clair-Thompson, H. (2015). Gender differences in adolescents' academic motivation and classroom behaviour. Educational Psychology, 35(5), 541-556.

Deci, E. L., \& Ryan, R. M. (2010). Self-Determination. US: John Wiley $\&$ Sons, Inc.

Durik, A. M., Lovejoy, C. M., \& Johnson, S. J. (2009). A Longitudinal study of achievement goals for college in general: predicting cumulative GPA and diversity in course selection. Contemporary Educational Psychology, 34(2), 113-119.

Ersanl1, C. Y. (2015). The relationship between students' academic selfefficacy and language learning motivation: A study of 8th graders. Procedia-Social and Behavioral Sciences, 199, 472-478. 
Feldman, D. B., \& Kubota, M. (2015). Hope, self-efficacy, optimism, and academic achievement: distinguishing constructs and levels of Specificity in predicting college grade-point average. Learning and Individual Differences, 37, 210-216.

Foote, A. W., Piazza, D., Holcombe, J., Paul, P., \& Daffin, P. (1990). Hope, self-esteem and social support in persons with multiple sclerosis. Journal of Neuroscience Nursing, 22(3), 155-159.

Fortier, M. S., Vallerand, R. J., \& Guay, F. (1995). Academic motivation and school performance: toward a structural model. Contemporary Educational Psychology, 20(3), 257-274.

Helmer, R., Jacquelyn N, \& Grolnick, W. S. (2016). Children's coping with academic failure: Relations with contextual and motivational resources supporting competence. The Journal of Early Adolescence, 36(8), 1017-1041.

Husain, U. K. (2014). Relationship between self-efficacy and academic motivation. Paper presented at the International Conference on Economics, Education and Humanities, Indonesia.

Komarraju, M., Karau, S. J., \& Schmeck, R. R. (2009). Role of the big five personality traits in predicting college students' academic motivation and achievement. Learning and Individual Differences, 19(1), 47-52.

Linnenbrink, E. A., \& Pintrich, P. R. (2002). Motivation as an enabler for academic success. School Psychology Review, 31(3), 313.

Lopez, S. J., Rose, S., Robinson, C., Marques, S. C., \& Pais-Ribeiro, J. (2009). Measuring and promoting hope in schools. In M. J. Furlong, R. Gilman \& E. S. Huebner (Eds.), Handbook of Positive Psychology in the Schools (pp. 37-51). UK: Routledge.

Marques, S. C., Lopez, S. J., \& Pais-Ribeiro, J. (2011). Building hope for the future: A program to foster strengths in middle-school Students. Journal of Happiness Studies, 12(1), 139-152.

Martin, M., \& Greenwood, W. C. (1995). Solving your Child's schoolrelated problems. New York: HarperPerenniel. 
Midgley, C., Maehr, M. L., Hruda, L. Z., Anderman, E., Anderman, L., Freeman, K. E., . . . Urdan, T. (2000). Manual for the patterns of adaptive learning scales (PALS). Retrieved from http://www.umich.edu/ pals/PALS\%202000V12Word97.pdf

PiñaWatson, B., López, B., Ojeda, L., \& Rodriguez, K. M. (2015). Cultural and cognitive predictors of academic motivation among mexican American adolescents: Caution against discounting the impact of cultural processes. Journal of Multicultural Counseling and Development, 43(2), 109-121.

Rojas, J. P. (2015). The relationships among creativity, grit, academic motivation, and academic success in college students. university of Kentucky, USA.

Rowell, L., \& Hong, E. (2013). Academic Motivation: Concepts, Strategies, and Counseling Approaches. Professional School Counseling, 16(3), 158-171.

Ryan, R. M., \& Deci, E. L. (2000). Self-Determination Theory and the facilitation of intrinsic motivation, social development, and wellbeing. American Psychologist, 55(1), 68.

Sarıkoc, G., \& Oksuz, E. (2017). Academic motivations and academic self-efficacy of nursing students Journal of Clinical and Analytical Medicine, 8(1), 47-51. doi: 10.4328/JCAM.4654

Snyder, C., Rand, K. L., \& Sigmon, D. R. (2002). Hope theory. United States of America: Oxford University Press, Inc.

Snyder, C., Shorey, H. S., \& Rand, K. L. (2008). Using hope theory to teach and mentor academically At-Risk Students Handbook of the Teaching of Psychology (pp. 170). US: Blackwell Publishing Ltd.

Snyder, C. R., Shorey, H. S., Cheavens, J., Pulvers, K. M., Adams III, V. H., \& Wiklund, C. (2002). Hope and Academic Success in College. Journal of Educational Psychology, 94(4), 820.

Sympson, S. C., \& Snyder, C. (1997). Development and Initial validation of the domain specific hope scale. University of Kansas, Lawrence. 
Turgut, M. (2013). Academic self-efficacy beliefs of undergraduate mathematics education students. Acta Didactica Napocensia, 6(1), $33-40$.

Vallerand, R. J., Pelletier, L. G., Blais, M. R., Briere, N. M., Senecal, C., $\&$ Vallieres, E. F. (1992). The academic motivation scale: A measure of intrinsic, extrinsic, and a-motivation in education. Educational and Psychological Measurement, 52(4), 1003-1017.

Walker, C. O., Greene, B. A., \& Mansell, R. A. (2006). Identification with academics, intrinsic/extrinsic motivation, and self-efficacy as predictors of cognitive engagement. Learning and individual differenceS, 16(1), 1-12.

Wigfield, A., Guthrie, J. T., Tonks, S., \& Perencevich, K. C. (2004). Children's motivation for reading: domain specificity and instructional influences. The Journal of Educational Research, 97(6), 299-310.

Wood, J. L., Hilton, A., \& Hicks, T. (2014). Motivational factors for academic success: perspectives of african american males in the. The National Journal of Urban Education and Practice, 7(3), 247-265.

Zajacova, A., Lynch, S. M., \& Espenshade, T. J. (2005). self-efficacy, stress, and academic success in college. Research in Higher Education, 46(6), 677-706.

Zimmerman, B. J. (2008). Investigating self-regulation and motivation: historical background, methodological developments, and future prospects. American Educational Research Journal, 45(1), 166-183.

Zimmerman, B. J., Bandura, A., \& Pons, M., M (1992). Self-motivation for academic attainment: The role of self-efficacy beliefs and personal goal setting. American Educational Research Journal, 29(3), 663-676.

\section{Citation of this Article:}

Arooj., H., \& Ijaz, T. (2019). An investigation of efficacy and hope as predictors of academic motivation. Pakistan Journal of Education, 36(1), 81-98. 